\title{
Maternal Attachment and Children's Quality of Life: The Mediating Role of Self-Compassion and Parenting Stress
}

Helena Moreira, Maria João Gouveia, Carlos Carona, Neuza Silva, \& Maria Cristina Canavarro

Faculty of Psychology and Educational Sciences, University of Coimbra, Coimbra, Portugal.

\section{Cite as:}

Moreira, H., Gouveia, M. J., Carona, C., Silva, N., \& Canavarro, M. C. (2015).

Maternal attachment and children's quality of life: The mediating role of self-

compassion and parenting stress. Journal of Child and Family Studies, 24(8), 2332-

2344. doi:10.1007/s10826-014-0036-Z

URL: http://link.springer.com/article/10.1007\%2Fs10826-014-0036-Z\#page-1

\author{
H. Moreira $\bowtie$ \\ Cognitive-Behavioral Research Centre (CINEICC), Faculty of Psychology and \\ Educational Sciences, University of Coimbra, Coimbra, Portugal. \\ Rua do Colégio Novo, Apartado 6153, 3001-802 Coimbra, Portugal. \\ E-mail: hmoreira@fpce.uc.pt
}

\section{Acknowledgments}

This work was supported by the Portuguese Foundation for Science and Technology under Grant [SFRH/BPD/70063/2010]. 


\begin{abstract}
The stress parents feel in their parenting roles and the ways they relate to themselves in difficult or distressing situations, such as with self-compassion, are influenced by their attachment orientations and may account for the well-known association between the quality of parents' attachment to their own parents and their children's developmental outcomes. We explored the association between self-compassion and parenting stress and their mediating role in the link between mothers' attachment orientations and children's quality of life (QoL). A total of 171 family dyads composed of a child/adolescent aged 8-18 years and the child's mother participated in the study. Mothers completed self-report measures of attachment toward their own mother (ECRRS), self-compassion (SELFCS), and parenting stress (PSI). The children completed a measure of QoL (KIDSCREEN-10). The current study showed that mothers' attachment to their own mother was indirectly associated with their child's QoL through self-compassion and parenting stress. Specifically, higher levels of attachment-related anxiety and avoidance among mothers toward their own mother were associated with worse children's QoL through lower levels of mothers' self-compassion and higher levels of parenting stress. These results reveal an important pathway linking mothers' attachment to their child's QoL and underline the importance of designing parenting programs aimed at reducing parenting stress that simultaneously help parents to become more compassionate toward themselves.
\end{abstract}

Keywords: attachment; parenting stress; self-compassion; children's quality of life; parenting. 


\section{Introduction}

One of the most significant determinants of children's social-emotional functioning is the quality of care provided by their main attachment figures, usually the parents (Ainsworth, Blehar, Waters, \& Wall, 1978; Bowlby, 1969; George \& Solomon, 1996; Mikulincer \& Shaver, 2007). Grounded in attachment theory, numerous studies have suggested that parental caregiving behaviors are strongly influenced by parents' attachment orientations in relation to their own parents, which, in turn, influence the attachment orientations of children and their psychological adjustment (Cowan, Cohn, Cowan, \& Pearson, 1996; Cowan, Cowan, \& Mehta, 2009; van IJzendoorn, 1995). Research has also shown that insecurely attached parents feel more stressed in their parenting roles (Rholes, Simpson, \& Friedman, 2006) and that parenting stress may be associated with less positive parenting behaviors and worse children's adaptation outcomes (Abidin, 1992; Deater-Deckard, 2004). The way parents relate to themselves in times of failure or difficulty, such as with self-compassion or selfcriticism, is strongly associated with their attachment histories (Gilbert, 2005) and may be expected to affect their parenting behaviors and, consequently, their children's psychological well-being. However, little is known about the link between self-compassion and parenting stress and the potential mediating role of these factors on the associations between mothers' attachment orientations and children's quality of life (QoL).

Parenting is one of the most significant and gratifying experiences in parents' lives, although it is also one of the most demanding. Parents are inevitably faced with numerous daily stressors associated with parenting, which may influence their individual adjustment as well as their relationship with their children and, ultimately, their children's own adjustment (Webster-Stratton, 1990). As a result, parents may experience greater or lesser degrees of parenting stress, which has been defined as the stress that arises from a perceived discrepancy between the actual demands of parenting and a parent's personal and social resources (e.g., knowledge, parenting skills, social support) to cope with those demands (Abidin, 1992; Deater-Deckard, 2004). Parenting stress is a well-recognized risk factor for negative parenting behaviors, such as a stricter disciplinary style or less nurturing behavior (Anthony et al., 2005; Crnic \& Low, 2002), and children's maladaptive development and psychopathology (Deater-Deckard, 2004).

The degree to which parents experience parenting stress may depend on several factors, including their attachment orientation. In fact, parental attachment has been presented as a strong predictor of parental caregiving behavior (George \& Solomon, 1996; Gillath, Shaver, \& Mikulincer, 2005; Mikulincer \& Shaver, 2007), although studies focusing specifically on parenting stress are scarce and have produced mixed results. For instance, Rholes et al. (2006) found that avoidant parents experienced more parenting stress, reported less desire 
to become parents, and felt that parenting was less meaningful and satisfying after the birth of their children. However, Nygren, Carstensen, Ludvigsson, and Frostell (2012) found a positive association between parenting stress and attachment anxiety, and Vasquez, Durik, and Hyde (2002) found a positive association between parenting stress and fearful attachment. All of these studies converge in suggesting that insecure attachment, either more avoidant or more anxious, may lead to increased levels of parenting stress. Parenting may be stressful for avoidant individuals because they usually find it difficult to assume caregiving roles, both in relation to other adults and in relation to their children (Gillath et al., 2005; Rholes et al., 2006), given their discomfort with close relationships and their strong need for independence and self-sufficiency (Mikulincer \& Shaver, 2007). Moreover, these individuals have less desire to have children (Rholes, Simpson, Blakely, Lanigan, \& Allen, 1997; Rholes et al., 2006), which may also lead them to feel more stressed in their parenting role. With regard to anxiously attached parents, their hyperactivating strategies of emotion regulation may increase their stress when dealing with the daily stressors of rearing a child. Moreover, these individuals tend to be selfcentered and worry about their own attachment needs (Mikulincer \& Shaver, 2007), and they may feel extremely distressed when other people need their assistance (Mikulincer, Shaver, Gillath, \& Nitzberg, 2005).

Another factor that may lead parents to evaluate their personal resources as insufficient to cope with parenting demands is the way parents usually relate to themselves in difficult situations, such as through selfcompassion. Self-compassion is an adaptive way of self-to-self relating (Gilbert \& Procter, 2006; Neff, 2009 , 2012) that can be simply understood as compassion toward the self (Neff, 2009). Although there is no established definition of self-compassion, it can be broadly described as an ability that involves the recognition and the desire to alleviate one's suffering with kindness and care and in a non-judgmental way, recognizing that we all share a common human condition (i.e., that all human beings are imperfect and fragile) (Neff, 2003a, 2009, 2012). Specifically, self-compassion was described by Neff (2003a) as a construct consisting of three bipolar dimensions: self-kindness versus self-judgment (facing difficulties, failures, and suffering with a caring and understanding attitude instead of being self-critical and judgmental), mindfulness versus over-identification (mindful awareness of painful emotions or experiences instead of ignoring, avoiding, or ruminating on negative events), and common humanity versus isolation (acknowledging that one's painful experiences are part of a common human condition instead of feeling isolated, ashamed, or different). Self-compassion can also be understood from the perspective of the evolutionary model of social mentality theory proposed by Gilbert (1989, 2005). According to this perspective, compassion emerges from a caregiving mentality that orients the individual to be caring and protective of the other, thereby increasing the other's chances of survival (Gilbert, 2005). 
Because social mentalities can be applied to self-to-self relating (Gilbert \& Irons, 2005), self-compassion can be viewed as a healthy self-to-self relationship in which the individual is able to activate a caregiving mentality in self-to-self relating, particularly in moments of suffering and failure (Gilbert \& Procter, 2006). Within this evolutionary perspective, self-compassion is associated with a soothing and affiliative system of affect regulation that guides attachment and caregiving behaviors and is responsible for generating feelings of contentment, soothing, safeness, and connectedness (Depue \& Morrone-Strupinsky, 2005; Gilbert, 2005, 2009; Gilbert \& Choden, 2013; for a review of the three emotional regulation systems, see Gilbert, 2005). Individuals with low levels of self-compassion usually find it difficult to access the soothing system, whereas the threat and/or drive systems are easily and frequently activated (Gilbert, 2009).

It has been suggested that the adequate development of the soothing system, and therefore the development of self-compassion, is associated with early experiences of care with attachment figures (Gilbert, 2005; Gilbert \& Choden, 2013; Gilbert \& Procter, 2006; Neff \& Beretvas, 2012; Neff \& McGehee, 2010). According to attachment theory (Bowlby, 1969), the availability and responsivity of an attachment figure when the child feels threatened is key to the development of security (i.e., the feeling that one can rely on others as a source of support and protection, can explore the environment safely, and can engage rewardingly with others; Mikulincer \& Shaver, 2004). If the caregiver is consistently supportive and caring, the child learns that proximity seeking is an effective strategy of emotion regulation, and he or she develops a sense of security and connectedness. In this optimal caring environment, the child develops internal working models of the self and others as being reliable and worthy of care and love (Collins, Guichard, Ford, \& Feeney, 2004; Mikulincer \& Shaver, 2007), the soothing system develops adequately, and the individual cultivates a compassionate way of self-to-self relating (Gilbert, 2005; Gilber \& Procter, 2006). These positive experiences promote the development of emotional memories of being soothed, protected, and cared for (Lee, 2012), allowing the individual to regulate his or her emotions with affection, warmth, and care when needed. However, when caregivers are inadequately or inconsistently available or responsive, the child develops secondary strategies of emotion regulation characterized by anxiety or avoidance (i.e., hyperactivation or deactivation, respectively), and a sense of attachment security is not attained (Mikulincer \& Shaver, 2004, 2007). It has been suggested that growing up in neglectful, abusive, or hostile environments leads to insufficient development of the soothing system and to the emergence of self-criticism rather than self-compassion (Gilber \& Procter, 2006). Individuals raised in these relational contexts have few or no available emotional memories of being loved and soothed when they need to regulate their emotions in difficult moments (Gilbert \& Irons, 2005; Lee, 2012). A few 
previous studies have directly explored the associations among attachment styles, early experiences with caregivers, and levels of self-compassion. In one study, Neff and McGehee (2010) found that teenagers with low levels of self-compassion were more likely to have critical mothers, dysfunctional family environments, and insecure attachment styles. Similar results were found in a subsequent study (Neff \& Beretvas, 2012), in which a positive association was found between secure attachment and self-compassion and a negative link was found between preoccupied and fearful attachment styles and self-compassion.

Self-compassion has been studied as an individual capacity or internal resource associated with a variety of positive outcomes, such as greater life satisfaction and feelings of social connectedness (Neff, 2003a), less anxiety and depression (Krieger, Altenstein, Baettig, Doerig, \& Holtforth, 2013; Neff, 2003a), higher levels of optimism, happiness, wisdom, positive affect, curiosity, and personal initiative (Neff, Rude, \& Kirkpatrick, 2007), or greater mastery goals among students (Neff, Hseih, \& Dejitthirat, 2005). Self-compassion has also been found to be a protective factor that helps the individual cope more adaptively with challenging life circumstances, including infertility (Galhardo, Cunha, Pinto-Gouveia, \& Matos, 2013), cancer (Pinto-Gouveia, Duarte, Matos, \& Fráguas, 2013), post-traumatic stress disorder (Thompson \& Waltz, 2008), aging (Allen, Goldwasser, \& Leary, 2012), and pain (Wren et al., 2012). However, until recently, the protective role of selfcompassion in interpersonal contexts has not been explored. For instance, Neff and Beretvas (2012) found that self-compassionate individuals reported greater well-being in their relationships (i.e., felt more worthy, happy, and authentic and were better able to express opinions within their relationship) and were described by their partners as more caring, accepting, and supportive of their partner's autonomy. In another study, Yarnell and Neff (2012) found that college undergraduates with higher levels of self-compassion experienced a greater sense of well-being within relationships, felt less emotional turmoil when resolving a relationship conflict, and were more likely to compromise and less likely to self-subordinate in situations of conflict with mothers, fathers, best friends, and romantic partners.

Despite these interesting results suggesting the relevance of self-compassion in the promotion of healthy relationships, the study of this personal resource in interpersonal contexts is still in its infancy. In addition, to the best of our knowledge, no studies have explored the association of self-compassion with parenting dimensions, although it is reasonable to expect that the way parents relate to themselves would have a significant influence on the way they see themselves as parents and on how they cope with the challenges of parenting. Self-compassionate individuals are expected to be warmer, more caring, and more supportive of their 
children and to be less stressed by the challenges of parenting, which may have a positive impact on children's well-being.

The present study explored the mediating role of self-compassion and parenting stress in the association between parents' attachment orientations and children's QoL. QoL was chosen as the children's outcome because it is an extensively used indicator of children's well-being in different areas of life. With regard to parents' attachment assessment, contrary to previous studies (Neff \& Beretvas, 2012; Neff \& McGehee, 2010), the current study adopted a dimensional perspective on adult attachment by assessing the two dimensions that are currently accepted to underlie individual differences in the organization of the attachment system: attachment-related anxiety and attachment-related avoidance. Attachment anxiety is characterized by sensitivity to rejection and abandonment and reflects the extent to which people worry about the other's availability or support in times of need, whereas attachment avoidance is characterized by discomfort with intimacy and closeness in relationships and reflects the degree to which individuals distrust their partner's good intentions and strive to maintain emotional distance and independence from their partner (Brennan, Clark, \& Shaver, 1998). It has been demonstrated that the correlation between attachment anxiety and/or avoidance in different relational domains is not as strong as expected and that there is substantial variability in people's working models (Baldwin, Keelan, Fehr, Enns, \& Kohs-Rangarajoo, 1996; Fraley, Heffernan, Vicary, \& Brumbaugh, 2011; Klohnen, Weller, Luo, \& Choe, 2005). Therefore, we adopted a contextual assessment of attachment by specifically assessing attachment to the mother or mother-like figure. We chose to assess the mother because we intended to assess parents' attachment to their own parents, and the mother is usually the main parental attachment figure. We hypothesized that higher levels of parental attachment-related anxiety and avoidance would be associated with decreased children's QoL through lower levels of self-compassion, which, in turn, would be associated with higher parenting stress.

\section{Method}

\section{Participants}

The sample included 171 family dyads composed of children/adolescents aged 8-18 years and their mothers. Of these, 133 were recruited in school settings, and the remaining 38 were recruited in the general community at the participants' homes between January and February 2014. The following inclusion criteria were considered for the children: (1) age between 8 and 18 years at the time of recruitment; (2) absence of a chronic health condition or developmental delay; and (3) ability to understand and answer the questionnaires. Given the objective of analyzing family dyads in the present study, only mothers who agreed to participate and who 
authorized their child to participate in the study were considered. The mean age of mothers was 40.76 years old $(S D=5.36$; range: $27-55)$, and the majority were married or living with a partner $(n=149 ; 87.6 \%)$. With regard to education levels, $104(60.8 \%)$ mothers had completed basic or secondary studies, $66(38.6 \%)$ had completed graduate or post-graduate studies, and one did not report her education level $(0.6 \%)$. The mean age of children was 10.56 years old $(S D=2.61$; range: $8-18)$, and an equivalent number of boys $(85 ; 49.7 \%)$ and girls $(86$; $50.3 \%$ ) participated in the study.

\section{Procedure}

In strict agreement with the country's legal requirements, authorization for sample collection was first obtained from the National Commission for Data Protection and then from the Direction Board of the Central School Unit of Coimbra-South. Nine classes of five primary and elementary schools in the central region of Portugal were selected to obtain the intended sample size (i.e., at least 148 participants). The intended sample size was determined based on the power tables presented by Fritz and MacKinnon (2007) for mediation models using the bias-corrected bootstrap test of mediation, considering small-to-medium $\alpha$ and $\beta$ paths and .80 power. The parents were given a letter explaining the study, the informed consent form, and a packet with questionnaires to be completed at home and returned a week later. Informed consent was obtained from all parents, and informal assent was obtained from children. Children/adolescents who were allowed to participate completed the questionnaires in the classroom. During the questionnaire administration, a researcher was present to assist students in any queries regarding completion procedures. A total of 241 children/adolescents and their parents were invited to participate, and $186(77.18 \%)$ completed the questionnaires. Forty-two participants were excluded due to the participation of only one member of the dyad or to an incomplete questionnaire.

Additionally, 11 father-child dyads were excluded from the study due to their low number.

A subset of 38 participants was recruited in the general community. These dyads were also composed by school-aged children/adolescents attending public schools and were personally recruited in the community by the researchers. An envelope containing an informative letter, the informed consent form, and the self-report questionnaires was given to participants, who completed the assessment protocol at home and returned it to the researcher at a pre-established date. Informed consent was obtained from all parents, and informal assent was obtained from children. Parents were informed that they could assist their children in understanding the items of the questionnaires but could not influence their answers.

\section{Measures}


Mothers completed a battery of self-report measures related to attachment, self-compassion, and parenting stress, and children completed a questionnaire on QoL. Cronbach's alphas for each measure, in the present study, are presented in Table 1.

Attachment. The Portuguese version of the Experiences in Close Relationships - Relationship Structures questionnaire (ECR-RS; Moreira, Martins, Gouveia, \& Canavarro, 2014; Fraley et al., 2011) was used to assess maternal attachment-related anxiety (e.g., "I'm afraid that this person may abandon me") and avoidance (e.g., "It helps to turn to this person in times of need") toward their own mother or mother-like figure. Although this self-report instrument was designed to measure attachment anxiety and avoidance in different close relationships (mother or mother-like figure, father or father-like figure, romantic partner, and best friend), for the purposes of the current study, only attachment to the mother or mother-like figure was used. Participants were instructed to respond the questions considering their current relationship with their mother/mother-like figure or, if their mother/mother-like figure had passed away, considering the way they felt when she was alive. The ECRRS is composed of nine items rated on a seven-point Likert scale ranging from 1 (strongly disagree) to 7 (strongly agree). The subscale score consists of the mean of the items, with higher scores indicating higher attachment avoidance and anxiety. Fraley et al. (2011) found the ECR-RS to be a psychometrically sound measure of the two attachment dimensions in the four relational domains and provided evidence of its reliability (Cronbach's $\alpha$ ranged from .85 to .92) and validity. The Portuguese version (Moreira et al., 2014) revealed adequate reliability (Cronbach's $\alpha$ ranged from .72 to .91) and construct validity (convergent and known-groups) and confirmed the original two-factor structure.

Self-compassion. Levels of self-compassion were assessed by the Portuguese version of the SelfCompassion scale (SCS; Castilho \& Pinto-Gouveia, 2011; Neff, 2003b). This instrument has 26 items rated on a 5-point Likert scale that ranges from 1 (almost never) to 5 (almost always), and measures six components of self-compassion: Self-kindness (e.g., "I'm tolerant of my own flaws and inadequacies"), Self-judgment (e.g., "When times are really difficult, I tend to be tough on myself”), Common Humanity (e.g., "I try to see my failings as part of the human condition"), Isolation (e.g., "When I fail at something that's important to me, I tend to feel alone in my failure"), Mindfulness (e.g., "When something upsets me, I try to keep my emotions in balance"), and Over-identification (e.g., "When something upsets me, I get carried away with my feelings"). After reverse-coding negative items, it is possible to obtain a global measure of self-compassion by estimating the mean of the 26 items, with higher scores indicating higher self-compassion. In the current study, only the total score of self-compassion was used. The original SCS (Neff, 2003b) has shown good reliability $(\alpha=.92)$, 
temporal stability $(r=.93)$, and construct validity (convergent and discriminant). A first-order model (six-factor model) and a second-order model (with a single higher-order factor of self-compassion) were confirmed through confirmatory analyses in two different samples. The Portuguese version of SCS (Castilho \& Pinto-Gouveia, 2011) has also exhibited good psychometric properties, including adequate reliability $(\alpha=.89)$, temporal stability $(r=.78)$, and construct validity (convergent and discriminant).

Parenting stress. To assess the distress associated with the parental role, the Parental Distress subscale of the Portuguese version of the Parenting Stress Index - Short Form (PSI-SF; Abidin, 1995; Santos, 1997) was used. This subscale has 12 items that are answered on a 5-point Likert scale ranging from 1 (completely disagree) to 5 (completely agree). It assesses several aspects related to the distress of parenting, such as life restrictions due to the demands of child-rearing (e.g., "I feel trapped by my responsibilities as a parent"). The total score consists of the sum of the 12 items, with higher scores indicating higher levels of parental stress. The PSI-SF is one of the most commonly used measures of parenting stress. Although it is intended for parents of children 12 years and younger, it has been considered appropriate for use with parents of both children and adolescents (e.g., Schaaijk, Roeleveld-Versteegh, \& Baar, 2013; Streisand, Braniecki, Tercyak, \& Kazak, 2001). The PSI-SF has good psychometric properties, including adequate internal consistency (Cronbach's $\alpha=.78$ ) and test-retest stability $(r=.61)$ in the parental distress subscale. It has also shown adequate construct (convergent and discriminant) and predictive validity (Haskett, Ahern, Ward, \& Allaire, 2006). Similarly, the Portuguese version presented good psychometric properties, including adequate internal consistency in the parental distress subscale (Cronbach's $\alpha=.82)$ (Santos, 2008).

Children's quality of life. The children's QoL was assessed with the Portuguese self-report version of the KIDSCREEN-10 index (Matos, Gaspar, \& Simões, 2012; Ravens-Sieberer et al., 2010), a 10-item questionnaire that assesses the general subjective health and well-being ("Have you felt fit and well?"; "Have you had fun with your friends?") of children and adolescents between 8 and 18 years old. This measure is answered using a 5-point Likert scale that ranges from 1 (never; not at all) to 5 (always; extremely), and provides a global index of QoL. Standardized scores (0-100) were calculated, with higher scores indicating better QoL. The KIDSCREEN-10 index is a psychometrically sound, cross-cultural and standardized instrument of QoL (Ravens-Sieberer et al., 2010). The reliability (Cronbach's $\alpha=.82)$ and temporal stability $($ ICC $=.70)$ of the original version were adequate for the self-report, and the instrument demonstrated good criterion and construct validity (convergent, discriminant, and known-groups). The validation study of the Portuguese version (Matos et al., 2012) confirmed the original unidimensional structure of the scale, demonstrated its invariance 
across age groups, nationalities, and socio-economic levels, and showed adequate reliability (Cronbach's $\alpha=$ $.78)$.

\section{Data Analyses}

Data analyses were conducted using the statistical package for the social sciences (SPSS, version 20.0; IBM SPSS, Chicago, IL) and the PROCESS computational tool (Hayes, 2013). Descriptive statistics were computed for all socio-demographic and study variables. Both Chi-square tests and one-way ANOVAs were used to compare the two sample subgroups on socio-demographic and study variables. Pearson's bivariate correlation coefficients were computed to assess associations between variables, and their strength was classified according to the following guidelines: "small" for correlations around .10, "medium" for those near .30, and "large" for correlations at .50 or higher (Cohen, 1988). Correlations between the socio-demographic and study variables were analyzed to select the appropriate covariates for introduction into the mediation model.

To evaluate the indirect effect of attachment dimensions on children's QoL through self-compassion and parenting stress, a serial multiple mediator model was estimated ("model 6" in Hayes, 2013) using the PROCESS. In these models, children's QoL acted as the dependent variable (DV), attachment dimensions (attachment anxiety and avoidance) acted as the independent variables (IVs), and self-compassion and parenting stress acted as the mediators $\left(\mathrm{M}_{1}\right.$ and $\mathrm{M}_{2}$, respectively). The effects of the IVs on the proposed Ms, the effects of $\mathrm{M}_{1}$ and $\mathrm{M}_{2}$ on the DV partialling out the effect of the IVs and the other $\mathrm{M}$ variable, the direct effects of IVs on DV after controlling for $\mathrm{M}_{1}$ and $\mathrm{M}_{2}$, and the total effects of IVs on DV are presented in Figure 1. A bootstrapping procedure was used to assess the indirect effects (using 10000 resamples). This procedure creates 95\% bias-corrected and accelerated confidence intervals (BCa CIs) of the indirect effects. An indirect effect is significant if zero is not contained within the lower and upper CIs. The empirical power tables proposed by Fritz and MacKinnon (2007) for mediation models suggest that the sample size of the current study is sufficient to detect a mediated effect including small-to-medium $\alpha$ and $\beta$ paths (i.e., $\alpha$ and $\beta=0.26$ ) with a .80 power.

\section{Results}

\section{Preliminary Analyses}

Differences in socio-demographic and study variables between participants recruited in school settings $(n=133)$ and participants recruited in the general community $(n=38)$ were analyzed. Significant differences were found in children's sex, $\chi^{2}(1)=4.69, p=.030$, children's age, $F(1,169)=52.33, p<.001$, and mothers' age, $F(1,169)=10.31, p=.002$. Children and mothers recruited in school settings were younger than children and mothers recruited in the general community. In addition, while the majority of children recruited in schools 
were boys, the majority of children recruited in the community were girls. No significant differences were found in the mothers' marital status, $\chi^{2}(1)=0.15, p=.698$, and level of education, $\chi^{2}(1)=1.51, p=.220$. In addition, no differences were found in any study variable: mothers' attachment, Wilk's lambda $=0.99, F(2,168)=0.84, p$ $=.433$, self-compassion, $F(1,169)=2.30, p=.131$, parenting stress, $F(1,169)=1.24, p=.268$, and children's QoL, $F(1,169)=0.40, p=.530$. Given the absence of significant differences in the study variables the two subgroups were analyzed together.

\section{Descriptive Statistics and Correlations}

The means, standard deviations, and Pearson's inter-correlations for the study variables are presented in Table 1. The mean values of attachment dimensions were relatively low, ranging from 2.72 (anxiety) to 2.75 (avoidance) in a possible range of 1 to 7 . Levels of parenting stress $(M=27.55)$ were average considering the possible range of the scale (12 to 60$)$, as well as the levels of self-compassion $(M=3.29)$, considering the range of the SCS (1 to 5). Finally, the mean values of children's QoL $(M=78.63)$ were relatively high, considering the range of the KISCREEN scale (0 to 100).

With regard to the intercorrelations between study variables, attachment avoidance and attachment anxiety were both positively and moderately correlated with parenting stress and negatively and moderately correlated with self-compassion. Conversely, attachment dimensions were not significantly associated with children's QoL. Children's QoL was negatively and moderately associated with parenting stress but was not significantly associated with mother's self-compassion. Finally, self-compassion was negatively and highly correlated with parenting stress.

Bivariate associations between socio-demographic variables (children's age and sex, mother's age, education, and marital status) and the mediating and dependent variables were also analyzed to identify potential covariates. Significant correlations were found between children's sex $(0=$ boys; $1=$ girls $)$ and children's QoL $(r=-.22, p<.001)$; between children's age and children's QoL $(r=-.31, p<.001)$; and between mother's marital status $(0=$ not living with a partner, $1=$ married or living with a partner $)$ and self-compassion $(r=-.22, p$ $<.001)$. No other significant associations were found.

(Table 1 about here)

\section{Mediation Analysis}

Considering the significant associations between children's age and sex, mother's marital status, and some mediator or dependent variables, these sociodemographic variables were entered as covariates in the mediation model. In addition, given the evidence of significant differences between the two sample subgroups in 
some sociodemographic variables, the sample subgroup $(0=$ school; $1=$ general community $)$ was also entered as covariate in the model. As presented in Figure 1, the analysis of individual paths showed that attachment anxiety and avoidance were significantly associated with self-compassion $(b=-0.05, S E=0.02, p=.007 ; b=-0.08, S E$ $=0.03, p=.001$, respectively) in a model explaining $20.7 \%$ of the self-compassion variance $\left(R^{2}=.207, F(6,163)\right.$ $=7.08, p<.001)$. Attachment anxiety, attachment avoidance, and self-compassion were significantly associated with parenting stress $(b=0.65, S E=0.28, p=.021 ; b=0.86, S E=0.36, p=.019 ; b=-8.65, S E=1.10, p<.001$, respectively), explaining $43.6 \%$ of the parenting stress variance $\left(R^{2}=.436, F(7,162)=17.86, p<.001\right)$. Finally, children's QoL was associated with parenting stress $(b=-0.35, S E=0.17, p=.047)$ but was not associated with self-compassion $(b=0.48, S E=2.86, p=.867)$, attachment anxiety $(b=0.43, S E=0.63, p=.502)$, and attachment avoidance $(b=0.81, S E=0.82, p=.326)$ in a model explaining $16.0 \%$ of the QoL variance $\left(R^{2}=\right.$ $.160, F(8,161)=3.83, p<.001)$

A significant sequential indirect effect of attachment anxiety on children's QoL through selfcompassion and parenting stress was observed (point estimate $=-0.16, S E=0.10,95 \% \mathrm{BCaCI}=-0.44 /-0.02$ ). The data also demonstrated a significant indirect effect of attachment anxiety on children's QoL through parenting stress (point estimate $=-0.23, S E=0.17,95 \% \mathrm{BCaCI}=-0.68 /-0.01$ ). In contrast, self-compassion alone did not act as a mediator of the link between attachment anxiety and children's QoL (point estimate $=-0.03, S E$ $=0.17,95 \% \mathrm{BCaCI}=-0.43 / 0.28)$. The same pattern of results was found when attachment avoidance was the IV. A significant sequential indirect effect of attachment avoidance on children's QoL through self-compassion and parenting stress was found (point estimate $=-0.25, S E=0.15,95 \% \mathrm{BCaCI}=-0.66 /-0.04$ ). In addition, a significant specific indirect effect of attachment avoidance on children's QoL through parenting stress (point estimate $=-0.30, S E=0.19,95 \% \mathrm{BCaCI}=-0.85 /-0.04)$ was observed. Conversely, self-compassion alone did not act as a mediator of the association between attachment avoidance and children's QoL (point estimate $=-0.04$, $S E=0.26,95 \% \mathrm{BCaCI}=-0.61 / 0.44)$.

\section{(Figure 1 about here)}

\section{Discussion}

In the presented study we tested a mediation model linking mothers' attachment dimensions and children's QoL through mothers' self-compassion and parenting stress. Specifically, we found that higher levels of mothers' attachment-related anxiety and avoidance toward their own mother were associated with worse children's QoL_not directly, but through lower levels of mothers' self-compassion and higher levels of parenting stress. This mediation model was tested in a normative sample of children/adolescents and respective 
mothers, recruited in schools and in the community. This may explain the relatively low levels of attachmentrelated avoidance and anxiety, average parenting stress and self-compassion, and high children's QoL that characterize the current sample. Similar results have been found in studies using comparable samples of participants recruited in the general community. For instance, several studies reported levels of self-compassion (Castilho \& Pinto-Gouveia, 2011; Neff \& Beretvas, 2012; Thompson \& Waltz, 2008; Yarnell \& Neff, 2012), parenting stress (Reitman, Currier, \& Stickle, 2002; Santos, 2008), and children's QoL (Gaspar et al., 2012) very similar to the levels found in the present study. Additionally, in line with the results obtained from previous studies (Fraley et al., 2012; Moreira et al., 2014), we found that mothers exhibited low attachment-related anxiety and avoidance scores, which supports the assumption that the average individual is relatively secure in relationships, including the relationship with their maternal attachment figure (van Ijzendoorn \& Sagi, 1999). It would be interesting to test the same model in children/adolescents with poorer QoL and in mothers with higher levels of parenting stress, higher levels of attachment-related anxiety and avoidance, and lower levels of selfcompassion.

As expected, high levels of attachment-related anxiety and avoidance were associated with lower levels of self-compassion. This finding is in accordance with the studies developed by Neff and colleagues (Neff \& Beretvas, 2012; Neff \& McGehee, 2010), which demonstrated that secure attachment was positively linked to self-compassion, in contrast to insecure attachment styles (fearful and preoccupied), which were negatively linked with this construct. Fearful and preoccupied individuals are characterized by high levels of anxiety, which means that they hold negative beliefs about their self-worth and worry about being abandoned by others (Bartholomew \& Horowitz, 1991). We should note, however, that in both studies by Neff and colleagues, no significant association was found between self-compassion and the dismissive attachment style, which is characterized by high levels of avoidance and low levels of anxiety. Nevertheless, this finding does not exclude the possibility of an association with the avoidance dimension because high levels of avoidance also characterize fearful individuals. Our results suggest that both avoidance and anxiety are associated with the underdevelopment of self-compassion. These individuals may not have adequately learned to comfort and sooth themselves when they were distressed (Gilbert, 2005; Lee, 2012), and their soothing system is most likely underdeveloped and understimulated (Gilbert \& Irons, 2005). Avoidant individuals typically grow up with cold, rejecting, and emotionally distant parents who disapprove of and punish closeness and manifestations of vulnerability (Mikulincer \& Shaver, 2007). This situation typically fosters the development of deactivating strategies of emotional regulation, which are characterized by an effort to maintain emotional distance from 
others, to suppress or hide signs of need and vulnerability, and to turn off the attachment system when a threat is perceived (Gillath et al., 2005; Mikulincer \& Shaver, 2004, 2007). Therefore, it may be more difficult for these individuals to cope with challenges with a kind and warm attitude toward themselves because when they perceive a threat, they are likely to cope with it by suppressing or deactivating their attachment needs. In addition, these individuals have access to few or no memories of being soothed and loved, which may explain their difficulty in regulating their emotions with self-compassion. In contrast, high levels of anxiety reflect the use of hyperactivating strategies of emotion regulation. These strategies consist of the intensification of the primary proximity-seeking strategy and strong efforts to attain the desired closeness and support from an attachment figure by constantly expressing anxiety, vulnerability, and the need for care and support (Mikulincer \& Shaver, 2004, 2007). The chronic activation of the attachment system may make it difficult for the individual to regulate his or her emotions with a calm and kind attitude toward himself or herself, which may explain why attachment anxiety is negatively associated with self-compassion.

Moreover, it is interesting to note that insecure individuals are less likely to have access to so-called "self-caregiving representations", security-based self-representations that may be activated under distressing circumstances (Mikulincer \& Shaver, 2007) and that we hypothesize to be intrinsically related to selfcompassion. According to the model of attachment-system functioning and dynamics in adulthood (Mikulincer \& Shaver, 2003, 2007), self-caregiving representations result from the internalization of the soothing qualities of an available, caring, and sensitive attachment figure and help individuals cope with stressful situations with a self-caring and self-compassionate attitude. Because secure individuals have usually experienced numerous security-boosting interactions with a supportive attachment figure, they are likely to treat themselves in the same way, automatically activating self-caregiving routines in moments of stress. In contrast, because insecure individuals are less likely to have experienced positive interactions with attachment figures, they are likely to be unable to call upon these self-caregiving representations when they most need them. This suggestion supports our results, indicating that attachment security may be positively associated with self-compassion because of the likely development of self-caregiving representations.

According to our expectations and previous studies (Nygren et al., 2012; Rholes et al., 2006; Vasquez et al., 2002), higher levels of mothers' attachment-related anxiety and avoidance were also associated with increased parenting stress. The attachment orientation of parents is strongly associated with their caregiving behaviors (Gillath et al. 2005; Mikulincer \& Shaver, 2007), and several studies have shown that insecure mothers are less caring, warm, and supportive toward their children and feel more stressed in the parenting role 
(George \& Solomon, 1996; Rholes et al., 2006). According to attachment theory, internal working models of the self and others are linked to working models of caregiving (i.e., mental representations of oneself as a caregiver, of the child as a care recipient, and of parent-child relationships), shaping parents' behaviors, expectations, and feelings during parent-child interactions (George \& Solomon, 1996, 1999). Therefore, it is conceivable that parental attachment orientations may influence the degree of stress parents feel in the parenting role. Avoidant parents may feel more stressed because of their increased difficulty in assuming a caregiving role (Gillath et al., 2005; Rholes et al., 1997; Rholes et al., 2006). As a result of their efforts to maintain their deactivated or downregulated attachment system (Mikulincer \& Shaver, 2007), these individuals tend to maintain a safe emotional distance from others and feel uncomfortable when others are distressed and need support and help (Gillath et al., 2005). However, parenting requires parents to care for a child who is vulnerable, needs help and protection, and frequently emits signals of distress. According to Rholes et al. (2006), this situation represents an "approachavoidance conflict" (p. 282) because whereas avoidant parents may want to maintain an emotional distance and turn off their attachment system, caring for a child requires a sensitive and supportive response to the child's needs that keeps the parent's attachment system activated, possibly leading to parenting stress. Moreover, some studies have shown that avoidant individuals do not have a strong desire to become parents (Rholes et al., 1997; Rholes et al., 2006), which may also explain the higher levels of parenting stress these individuals usually feel.

Anxious parents may also feel uncomfortable in their parenting role. When their child needs support or emits signals of distress, they may feel emotionally overwhelmed, and their hyperactivating strategies may lead them to focus not only on the child's distress but also on their own emotional distress, which may explain their increased levels of parenting stress. It is interesting to note that previous studies on the role of attachment in compassionate and altruistic behaviors toward a needy person showed that attachment anxiety was not only inversely related to compassion but also positively related to personal distress (Mikulincer et al., 2005). This finding may be related to the chronically activated attachment system of these individuals and their selfpreoccupation, which may impede them from focusing on the other's needs. In the parenting context, we can suppose that the same hyperactivation of the attachment system and the consequent difficulty in regulating the parent's own negative emotions can occur, explaining the increased stress. Additionally, because of their negative working models of the self and caregiving, these individuals may feel a lack of confidence regarding their parental competence and their worth as parents, which may contribute to increased parenting stress.

In line with our expectations, the results of the present study showed a significant and negative association between maternal self-compassion and parenting stress. Several reasons may account for this 
association. First, self-compassionate mothers are likely to be less self-critical and, therefore, they may feel more confident in their ability to care for a child and less stressed by the challenges of parenting. Self-compassionate mothers may be more able to accept their shortcomings as parents as well as the limitations and failures of their children. The same argument explains why self-compassionate individuals report better relationship outcomes in the study by Neff and Beretvas (2012). These authors argued that the compassionate acceptance of human imperfections that characterizes self-compassionate individuals might lead to a greater acceptance of their romantic partner's imperfections and limitations, contributing to better relationship outcomes. Second, because self-compassionate individuals are better able to access the soothing system of affect regulation to regulate the threat and drive systems (Gilbert, 2005, 2014), they may feel less stressed by the daily challenges of rearing a child, managing to more effectively balance the negative emotions that may arise by calming and soothing themselves. Third, considering that self-compassionate individuals are more likely to co-create affiliative relationships based on a caregiving social mentality with others and with themselves, they are more motivated to display positive emotions and behaviors that include care, protection, reassurance, and guidance (Gilbert, 2005, 2014). For instance, Neff and Beretvas (2012) found that self-compassionate individuals were described by their romantic partners as more caring and accepting and as presenting higher levels of relatedness with their partners. Therefore, it may be hypothesized that self-compassionate parents are more likely to display caring and supportive behaviors toward their children, which may be associated with lower levels of parenting stress. It is important to note that although parenting stress alone mediated the link between mothers' attachment dimensions and children's QoL, self-compassion only exerted a mediating role through its association with parenting stress. Likewise, bivariate correlations showed a non-significant association between self-compassion and children's QoL. This result suggests that self-compassion (or the lack of it) has an important role in children's adjustment, but only indirectly via its influence on the mother's parenting behaviors and attitudes. In contrast, the association between parenting stress and children's QoL was significant, which is in accordance with previous investigations showing that parenting stress has a negative influence on children's adjustment. This finding may be explained by the potential relationship of parenting stress and more negative parenting practices, including inconsistent discipline or less warmth and responsiveness (Abidin, 1992; Anthony et al., 2005; Deater-Deckard, 2004). We may tentatively hypothesize that parents who are less stressed may have adopted more positive parenting practices, hence contributing to better QoL for their children. However, it should be noticed that only $16 \%$ of the QoL variance was explained in the current model and, as such, it is important not to forget that results obtained account only for a small part of the children's QoL. Future studies 
should explore the role of other relevant variables. In conclusion, the model tested in the present study suggests that mothers who are more anxious and avoidant in relation to their own mothers have a lower ability to relate to themselves with warmth and compassion and feel more stressed by parenting tasks and demands. This stress is subsequently associated with lower QoL reported by their children.

Several limitations should be noted. First, the cross-sectional design of the present study does not allow the positive identification of causal mechanisms and the establishment of directions between variables. Future longitudinal studies are warranted to determine the direction of associations over time. Second, because of the low number of fathers participating in the current study, we opted to exclude them from the analyses. Thus, the mediation model was only tested for mothers, which impedes the generalization of the results to fathers. Although the primary attachment figure is usually the mother, future studies should include mothers and fathers to ascertain whether the model applies equally to both. Third, the representativeness of the sample cannot be guaranteed because the large majority of parents and children were recruited from a convenience sample at public schools in the central region of Portugal. Fourth, although the majority of participants were collected through schools, a subset was collected in the general community. Therefore, two different sample collection procedures were used: children recruited from schools completed the questionnaires in the classroom, whereas children recruited in the community completed the questionnaires at home. Future studies should guarantee similar procedures to avoid potential biases due to different sampling. Fifth, although the contextual assessment of mothers' attachment allowed for a relatively unambiguous evaluation, some caution is needed in interpreting and generalizing the results to other attachment figures. It would be interesting for future studies to assess parents' attachment in relation to other key attachment figures, such as the father or the partner. Finally, no information was collected about the number of participants who responded to the ECR-RS considering their biological mother or another maternal figure. Similarly, no information was collected about the number of mothers or mother-like figures who were alive or had already passed way at the time of the study. It would be interesting for future studies to include these data.

Despite these limitations, the current study has several strengths and important implications. First, it provides an innovative contribution by exploring a new avenue to explain the association between parents' attachment and children's QoL. To the best of our knowledge, this is the first study to explore the mediating role of mothers' self-compassion and parenting stress in this association. Second, contrary to previous studies linking self-compassion and attachment, we adopted a dimensional perspective on attachment. It is currently accepted that anxiety and avoidance dimensions underlie all self-report measures of attachment and that the so-called 
attachment styles should be conceptualized in terms of areas in a two-dimensional space in which individuals are distributed (Brennan et al., 1998; Mikulincer \& Shaver, 2007). Finally, this study emphasizes the importance of adopting a dyadic perspective when addressing important issues in parenting by indicating a possible pathway linking mothers' functioning and their children's QoL.

With regard to the clinical implications, this study suggests that interventions aimed at reducing mothers' stress in their parenting role may benefit from the inclusion of self-compassionate training. For instance, exercises related to compassionate mind training (Gilbert \& Irons, 2005; Gilbert \& Procter, 2006) or mindful self-compassion training (Germer \& Neff, 2013) may be very useful to help parents develop selfcompassion skills that enable them to develop a new self-to-self relationship based on a caregiving social mentality. The inclusion of these exercises in parenting programs may be an effective way of helping parents to successfully manage parenting stress, which, in turn, is expected to have a positive effect on the QoL of their children. Parents may learn how to reduce their self-criticism with regard to their parenting skills or their child's behaviors and needs and to accept themselves and their children as imperfect individuals who deserve compassion. In addition, the results of this study suggest that working models of attachment may influence selfcompassion skills and parenting stress. This finding is in line with previous studies showing that the positive effects of compassionate imagery are influenced by individuals' attachment orientation (Rockliff et al., 2011). Although for individuals with insecure attachment styles, self-compassionate exercises may be extremely useful, these exercises may initially be experienced as difficult and even unpleasant tasks because the activation of the soothing and attachment system may lead to the emergence of difficult and unprocessed attachment-related emotions. Therefore, any parenting intervention that includes self-compassionate exercises should assess and seriously consider individual differences in attachment orientations. 


\section{References}

Abidin, R. R. (1992). The determinants of parenting behavior. Journal of Clinical Child Psychology, 21, 407412. doi: $10.1207 / \mathrm{s} 15374424 \mathrm{jccp} 2104 \_12$

Abidin, R. R. (1995). Parenting Stress Index: Professional Manual (3rd ed.). Odessa, FL: Psychological Assessment Resources, Inc.

Ainsworth, M., Blehar, M., Waters, E., \& Wall, S. (1978). Patterns of Attachment. Hillsdale, NJ: Erlbaum.

Allen, A. B., Goldwasser, E. R., \& Leary, M. R. (2012). Self-compassion and well-being among older adults. Self and Identity, 11, 428-453. doi:10.1080/15298868.2011.595082

Anthony, L. G., Anthony, B. J., Glanville, D. N., Naiman, D. Q., Waanders, C., \& Shaffer, S. (2005). The relationships between parenting stress, parenting behaviour and preschoolers' social competence and behaviour problems in the classroom. Infant and Child Development, 14, 133-154. doi: 10.1002/icd.385

Baldwin, M. W., Keelan, J. P. R., Fehr, B., Enns, V., \& Kohs-Rangarajoo, E. (1996). Social-cognitive conceptualizations of attachment working models: Availability and accessibility effects. Journal of Personality and Social Psychology, 71, 94-109. doi:10.1037/0022-3514.71.1.94

Bartholomew, K., \& Horowitz, L. M. (1991). Attachment styles among young adults: A test of a four-category model. Journal of Personality and Social Psychology, 61, 226-244. doi: 10.1037/0022-3514.61.2.226

Bowlby, J. (1969). Attachment. Vol. 1: Attachment and Loss. London: The Hogarth Press.

Brennan, K. A., Clark, C. L., \& Shaver, P. R. (1998). Self-report measurement of adult romantic attachment: An integrative overview. In J. A. Simpson, \& W. S. Rholes (Eds.), Attachment theory and close relationships (pp. 46-76). New York: The Guilford Press.

Castilho, P., \& Pinto-Gouveia, J. (2011). Auto-compaixão: Estudo da validação da versão portuguesa da Escala da Auto-Compaixão e da sua relação com as experiências adversas na infância, a comparação social e a psicopatologia. Psychologica, 54, 203-230.

Cohen, J. (1988). Statistical power analysis for the behavioral sciences. Hillsdale, NJ: Erlbaum.

Collins, N. L., Guichard, A. C., Ford, M. B., \& Feeney, B. C. (2004). Working models of attachment: New developments and emerging themes. In W. S. Rholes, \& J. A. Simpson (Eds.), Adult attachment: Theory, research, and clinical implications (pp. 196-239). New York: The Guilford Press.

Cowan, P. A., Cohn, D. A., Cowan, C. P., \& Pearson, J. L. (1996). Parents' attachment histories and children's externalizing and internalizing behaviors: Exploring family systems models of linkage. Journal of Consulting \& Clinical Psychology, 64, 53-63. doi: 10.1037/0022-006X.64.1.53 
Cowan, P. A., Cowan, C. P., \& Mehta, N. (2009). Adult attachment, couple attachment, and children's adaptation to school: An integrated attachment template and family risk model. Attachment \& Human Development, 11, 29-46. doi: 10.1080/14616730802500222

Crnic, K. A., \& Low, C. (2002). Everyday stresses and parenting. In M. Bornstein (Ed.), Handbook of parenting: Vol 5. Practical issues in parenting (pp. 243-267). Mahwah, NJ: Lawrence Erlbaum Associates.

Deater-Deckard, K. (2004). Parenting stress. New Haven, CT: Yale University Press.

Depue, R. A., \& Morrone-Strupinsky, J. V. (2005). A neurobehavioral model of affiliative bonding. Behavioral and Brain Sciences, 28, 313-395. doi:10.1016/j.biopsycho.2007.09.001

Fraley, R. C., Heffernan, M. E., Vicary, A. M., \& Brumbaugh, C. C. (2011). The Experiences in Close Relationships-Relationship Structures questionnaire: A method for assessing attachment orientations across relationships. Psychological Assessment, 23, 615-625. doi: 10.1037/a0022898

Fritz, M. S., \& MacKinnon, D. P. (2007). Required sample size to detect the mediated effect. Psychological Science, 18(3), 233-239. doi:10.1111/j.1467-9280.2007.01882.x.

Galhardo, A., Cunha, M., Pinto-Gouveia, J., \& Matos, M. (2013). The mediator role of emotion regulation processes on infertility-related stress. Journal of Clinical Psychology in Medical Settings, 20, 497-507. doi: $10.1007 / \mathrm{s} 10880-013-9370-3$

George, C., \& Solomon, J. (1996). Representational models of relationships: Links between caregiving and attachment. Infant Mental Health Journal, 17, 198-121. doi: 10.1002/(SICI)10970355(199623)17:3<198::AID-IMHJ2>3.0.CO;2-L

George, C., \& Solomon, J. (1999). Attachment and caregiving: The caregiving behavioral system. In J. Cassidy, \& P. R. Shaver (Eds.), Handbook of attachment: Theory, research, and clinical applications (pp. 649-670). New York, NY: The Guilford Press.

Germer, C. K., \& Neff, K. D. (2013). Self-compassion in clinical practice. Journal of Clinical Psychology, 69, 856-867. doi:10.1002/jclp.22021

Gilbert, P. (1989). Human nature and suffering. Hove: Lawrance Erlbaum.

Gilbert, P. (2005). Compassion and cruelty: A biopsychosocial approach. In P. Gilbert (Ed.), Compassion: Conceptualisations, research and use in psychotherapy (pp. 3-74). London, UK: Routledge.

Gilbert, P. (2009). Introducing compassion-focused therapy. Advances in Psychiatric Treatment, 15, $199-208$. doi: 10.1192/apt.bp.107.005264 
Gilbert, P. (2014). The origins and nature of compassion focused therapy. British Journal of Clinical Psychology, 53, 6-41. doi: 10.1111/bjc.12043

Gilbert, P., \& Choden (2013). Mindful compassion: Using the power of mindfulness and compassion to transform our lives. London, UK: Constable \& Robinson.

Gilbert, P., \& Irons, C. (2005). Focused therapies and compassionate mind training for shame and self-attacking. In P. Gilbert (Ed.), Compassion: Conceptualisations, research and use in psychotherapy (pp. 263-325). London, UK: Routledge.

Gilbert, P., \& Procter, S. (2006). Compassionate mind training for people with high shame and self-criticism: A pilot study of a group therapy approach. Clinical Psychology and Psychotherapy, 13, 353-379. doi: $10.1002 /$ cpp. 507

Gillath, O., Shaver, P. R., \& Mikulincer, M. (2005). An attachment-theoretical approach to compassion and altruism. In P. Gilbert (Ed.), Compassion: Conceptualisations, research and use in psychotherapy (pp. 121-147). London, UK: Routledge.

Hayes, A. F. (2013). Introduction to mediation, moderation, and conditional process analysis: A regressionbased approach. New York: The Guilford Press.

Klohnen, E. C., Weller, J. A., Luo, S., \& Choe, M. (2005). Organization and predictive power of general and relationship-specific attachment models: One for all, and all for one? Personality and Social Psychology Bulletin, 31, 1665-1682. doi:10.1177/0146167205278307

Krieger, T., Altenstein, D., Baettig, I., Doerig, N., \& Holtforth, M. G. (2013). Self-Compassion in depression: Associations with depressive symptoms, rumination, and avoidance in depressed outpatients. Behavior Therapy, 44, 501-513. doi: 10.1016/j.beth.2013.04.004

Lee, D. (2012). Recovering from trauma using compassion focused therapy. London, UK: Robinson.

Matos, M. G., Gaspar, T. \& Simões, C. (2010). Health-related quality of life in Portuguese children and adolescents. Psicologia: Reflexão e Crítica, 25(2), 230-237.

Mikulincer, M., \& Shaver, P. R. (2003). The attachment behavioral system in adulthood: Activation, psychodynamics, and interpersonal processes. In M. P. Zanna (Ed.), Advances in experimental social psychology (Vol. 35, pp. 53-152). New York: Academic Press.

Mikulincer, M., \& Shaver, P. R. (2004). Security-based self-representations in adulthood: Contents and processes. In W. S. Rholes, \& J. A. Simpson (Eds.), Adult attachment: Theory, research, and clinical implications (pp. 159-195). New York: The Guilford Press. 
Mikulincer, M., \& Shaver, P. R. (2007). Attachment in adulthood: Structure, dynamics, and change. New York: The Guilford Press.

Mikulincer, M., Shaver, P. R., Gillath, O., \& Nitzberg, R. A. (2005). Attachment, caregiving, and altruism: Boosting attachment security increases compassion and helping. Journal of Personality and Social Psychology, 89, 817-839. doi: 10.1037/0022-3514.89.5.817

Moreira, H., Martins, T., Gouveia, M. J., \& Canavarro, M. J. (2014). Assessing adult attachment across different contexts: Validation of the Portuguese version of the Experiences in Close Relationships ScaleRelationship Structures Questionnaire. Manuscript submitted for publication.

Neff, K. D. (2003a). Self-compassion: An alternative conceptualization of a healthy attitude toward oneself. Self and Identity, 2, 85-102. doi: 10.1080/15298860390129863

Neff, K. D. (2003b). Development and validation of a scale to measure self-compassion. Self and Identity, 2, 223-250. doi: 10.1080/15298860390209035

Neff, K. D. (2009). Self-Compassion. In M. R. Leary, \& R. H. Hoyle (Eds.), Handbook of Individual Differences in Social Behavior (pp. 561-573). New York: Guilford Press.

Neff, K. D. (2012). The science of self-compassion. In C. Germer, \& R. Siegel (Eds.), Compassion and Wisdom in Psychotherapy (pp. 79-92). New York: Guilford Press.

Neff, K. D., \& Beretvas, S. N. (2012). The role of self-compassion in romantic relationships. Self and Identity, 12, 78-98. doi: 10.1080/15298868.2011.639548

Neff, K. D., Hseih, Y., \& Dejitthirat, K. (2005). Self-compassion, achievement goals, and coping with academic failure. Self and Identity, 4, 263-287. doi: 10.1080/13576500444000317

Neff, K. D., \& McGehee, P. (2010). Self-compassion and psychological resilience among adolescents and young adults. Self and Identity, 9, 225- 240. doi: 10.1080/15298860902979307

Neff, K. D., Rude, S. S., \& Kirkpatrick, K. (2007). An examination of self-compassion in relation to positive psychological functioning and personality traits. Journal of Research in Personality, 41, 908-916. doi:10.1016/j.jrp.2006.08.002

Nygren, M., Carstensen, J., Ludvigsson, J., \& Frostell, A. S. (2012). Adult attachment and parenting stress among parents of toddlers. Journal of Reproductive and Infant Psychology, 30, 289-302. doi: $10.1080 / 02646838.2012 .717264$ 
Pinto-Gouveia, J., Duarte, C., Matos, M., \& Fráguas, S. (2013). The protective role of self-compassion in relation to psychopathology symptoms and quality of life in chronic and in cancer patients. Clinical Psychology and Psychotherapy, Advanced online publication. doi: 10.1002/cpp.1838

Ravens-Sieberer, U., Erhart, M., Rajmil, L., Herdman, M., Auquier, P., Bruil, J., \& European KIDSCREEN Group (2010). Reliability, construct and criterion validity of the KIDSCREEN-10 score: A short measure for children and adolescents' well-being and health-related quality of life. Quality of Life Research, 19, 1487-1500. doi:10.1007/s11136-010-9706-5

Reitman, D., Currier, R. O., \& Stickle, T. R. (2002). A critical evaluation of the Parenting Stress Index - Short Form (PSI-SF) in a Head Start population. Journal of Clinical Child and Adolescent Psychology, 31 (3), 384-392. Doi: 10.1207/S15374424JCCP3103_10.

Rholes, W. S., Simpson, J. A., Blakely, B. S., Lanigan, L., \& Allen, E. A. (1997). Adult attachment styles, the desire to have children, and working models of parenthood. Journal of Personality, 65, 357-385. doi: 10.1111/j.1467-6494.1997.tb00958.x

Rholes, W. S., Simpson, J. A., \& Friedman, M. (2006). Avoidant attachment and the experience of parenting. Personality and Social Psychology Bulletin, 32, 275-285. doi: 10.1177/0146167205280910

Rockliff, H., Karl, A., McEwan, K., Gilbert, J., Matos, M., \& Gilbert, P. (2011). Effects of intranasal oxytocin on 'compassion focused imagery'. Emotion, 11, 1388-1396. doi: 10.1037/a0023861

Santos, S. V. (1997). Versão portuguesa do Parenting Stress Index (PSI): Validação preliminar. In M. Gonçalves, I. Ribeiro, S. Araújo, C. Machado, L. Almeida, \& M. Simões (Eds.), Avaliação Psicológica: Formas e Contextos (Vol. 5, pp. 139-149).

Santos, S. V. (2008). Forma reduzida do Parenting Stress Index (PSI-SF): Estudo preliminar. Poster session at the XIII Conferência Internacional Avaliação Formas e Contextos, Braga, Portugal.

Schaaijk, N. M., Roeleveld-Versteegh, A. B., \& Baar, A. L. (2013). The interrelationships among paternal and maternal parenting stress, metabolic control, and depressive symptoms in adolescents with Type 1 Diabetes Mellitus. Journal of Pediatric Psychology, 38, 30-40. doi: 10.1093/jpepsy/jss096

Streisand, R., Braniecki, S., Tercyak, K. P., \& Kazak, A. E. (2001). Childhood illness-related parenting stress: The pediatric inventory for parents. Journal of Pediatric Psychology, 26, 155-162. doi: 10.1093/jpepsy/26.3.155

Thompson, B. L., \& Waltz, J. (2008). Self-Compassion and PTSD symptom severity. Journal of Traumatic Stress, 21, 556-558. doi: 10.1002/jts.20374 
van IJzendoorn, M. H. (1995). Adult attachment representations, parental responsiveness, and infant attachment: A meta-analysis of the predictive validity of the Adult Attachment Interview. Psychological Bulletin, 117, 387-403. doi: 10.1037/0033-2909.117.3.387

van IJzendoorn, M. H., \& Sagi, A. (1999). Cross-cultural patterns of attachment: Universal and contextual dimensions. In J. Cassidy \& P. R. Shaver (Eds.), Handbook of attachment: Theory, research, and clinical applications (pp. 713-734). New York: The Guilford Press.

Vasquez, K., Durik, A. M., \& Hyde, J. S. (2002). Family and work: Implications of adult attachment styles. Personality and Social Psychology Bulletin, 28, 874-886. doi: 10.1177/014616720202800702

Webster-Stratton, C. (1990). Stress: A potential disruptor of parent perceptions and family interactions. Journal of Clinical Child Psychology, 19, 302-312. doi: 10.1207/s15374424jccp1904_2

Wren, A. A., Somers, T. J., Wright, M. A., Goetz, M. C., Leary, M. R., Fras, A. M., .. Keefe, F. K. (2012). Selfcompassion in patients with persistent musculoskeletal pain: Relationship of self-compassion to adjustment to persistent pain. Journal of Pain and Symptom Management, 43, 759-770. doi: 10.1016/j.jpainsymman.2011.04.014

Yarnell, L. M., \& Neff, K. D. (2012). Self-compassion, interpersonal conflict resolutions, and well-being. Self and Identity, 12, 146-159. doi:10.1080/15298868.2011.649545 
Table 1. Descriptive statistics, Cronbach's alphas, and correlations among study variables

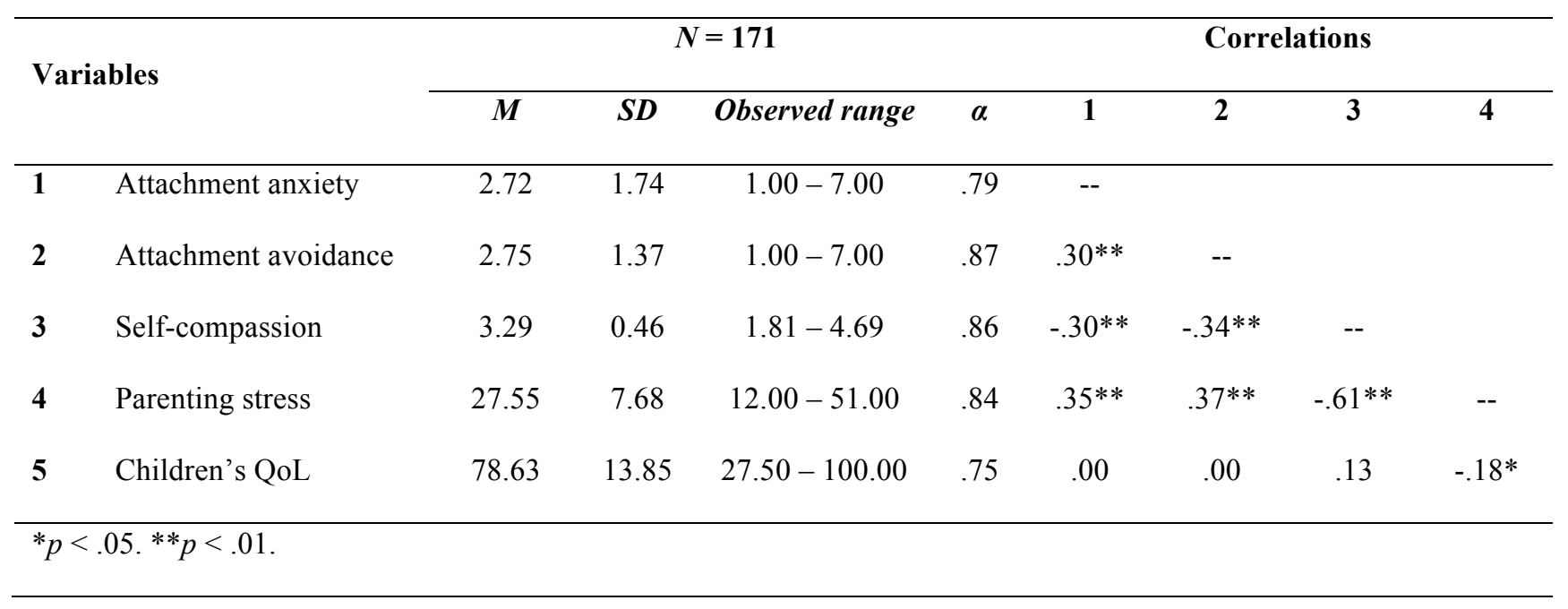




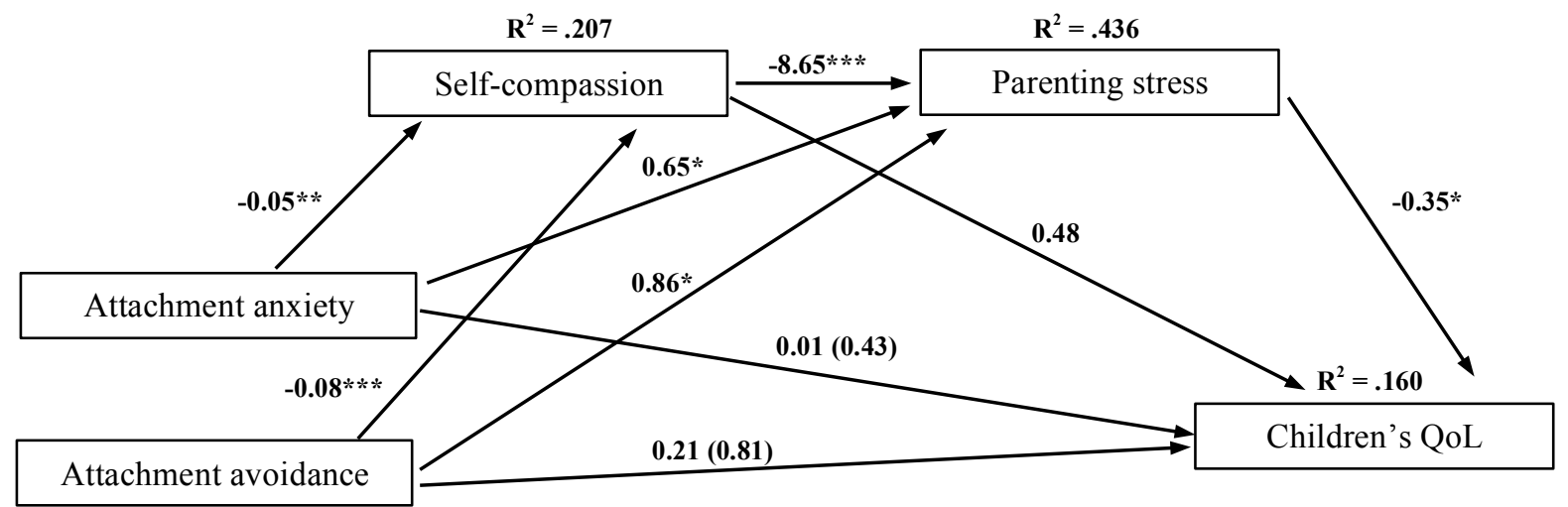

Figure 1. Statistical diagram of the serial multiple mediator model for the presumed influence of self-compassion and parenting stress on the association between attachment dimensions and children's QoL.

Note. Path values represent unstandardized regression coefficients. In the arrows linking attachment dimensions and children's QoL, the value outside parentheses represents the total effect of attachment anxiety or avoidance on children's QoL before the inclusion of the mediating variables. The value in parentheses represents the direct effect, from the bootstrapping analysis, of attachment anxiety and avoidance on children's QoL after inclusion of the mediators. ${ }^{*} p<.05 ; * * p<.01 ; * * * p .001$. 